\title{
The pedagogical utility of audio-visual aids on extrovert and introvert Iranian intermediate EFL learners' speaking ability
}

\section{Vaezi, Ramin}

Department of Foreign Languages, Khorasgan (Isfahan) Branch

Islamic Azad University, Isfahan, Iran (ramin.vaezi@khuisf.ac.ir)

Biria, Reza

Department of Foreign Languages, Khorasgan (Isfahan) Branch Islamic Azad University, Isfahan, Iran ( $\underline{\text { r biria@ yahoo.com) }}$

Azodi, Nazli

Department of Foreign Languages, Khorasgan (Isfahan) Branch Islamic Azad University, Isfahan, Iran (azodi_n@yahoo.com)

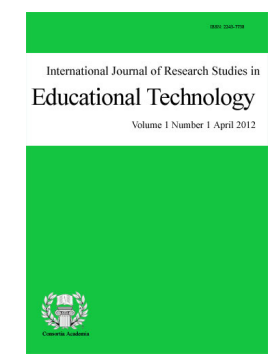

ISSN: $2243-7738$ Online ISSN: 2243-7746

OPEN ACCESS

\begin{abstract}
This study explored the relationship between the use of audio-visual aids to improve the speaking ability of Iranian intermediate EFL learners and their personality type; namely, introversion/extroversion. To this end, The Comprehensive English Language Test (CELT) was given to 250 students to homogenize the sample. Out of this, 120 students whose scores fell one standard deviation above and below the mean were regarded as intermediate. Having found the homogeneous participants, the Eysenck Personality Inventory (EPI) was given to them, through which 60 introverts and 60 extroverts were selected as the main participants. The selected participants were interviewed and rated by three native like speaker raters and after the treatment the same raters evaluated the interviewees. The obtained results through a two-way ANOVA indicated that there was a statistically significant difference between extroverts and introverts in terms of audio-visual aids, but the difference was not that prominent and, therefore, it cannot be recommended as an operational pedagogical factor. It can also be concluded that the extroverts were generally better at speaking than introverts; however, there again the difference was not statistically noteworthy.
\end{abstract}

Keywords: audio-visual aids; personality type; extroversion/introversion; speaking ability 


\section{The pedagogical utility of audio-visual aids on extrovert and introvert Iranian intermediate EFL learners' speaking ability}

\section{Introduction}

Speaking ability has been the topic of many language learning researches in recent years. Learning to speak a foreign language requires more than knowing its syntactic and semantic rules. Learners must also acquire the knowledge of how native speakers use the language in the context of structured interpersonal exchange, in which many factors interact. Therefore, it is difficult for EFL learners, especially adults, to speak the target language fluently and appropriately. In order to provide effective guidance in developing competent speakers of English, it is necessary to examine the factors affecting adult learners' oral communication, components underlying speaking proficiency, and specific skills or strategies used in communication.

Most people who learn a foreign language (here specifically English) in Iran, seem to learn, if ever, only the written form of it and almost always have problems with the spoken form of language. They usually have to overcome different shortcomings at different stages of learning English. When they first start talking, negative transfer of Persian into English can be seen very clearly. One frequently hears them telling a sentence like "*I called to my friend yesterday" which shows a direct translation of Persian into English and the researchers prefer to call it translated speaking. Although this is mostly because of the method(s) used in teaching, it can also be due to the material used in classes too. The problem is using the appropriate aid(s) and getting the desired result. We cannot expose the poor learner only to a teacher's speaking and expect him/her to get the ability to understand a film or listen to the audio and understand it. We can find many people who have an acceptable command of English, but only in written form, i.e. they can read an original text and understand it with no difficulty and if necessary they can produce a text in English as well. To make a long story short, it can be claimed that those who learn a foreign language in Iran are only able to learn the written form to an acceptable degree if ever and the spoken form is almost ignored. They may like to learn the spoken form on their own but the problem is they are liable to make too many mistakes.

To help with the aforementioned problem it seems that using audio-visual aids can be a great help. Media and technology can play an important role in the language arts program. Students live in an information age filled with a variety of technology and multimedia learning tools. In addition to books, newspapers, and many others, students have access to a range of media and communication technologies (e.g., voice mail, electronic mail, fax, internet, CD-ROM, laptop computers, camcorders, and many others). These texts and tools are useful for achieving the English language arts and objectives and offer opportunities for critical viewing and representing. Regardless of the text form, students must identify their purposes by determining what they need, where to find it, and how to access it. Moreover, they must select reliable and relevant information sources. As with other tools, the value of any technology depends upon how effectively students are able to use it. Students need to determine not only what they want to communicate but how they can do it most effectively. With appropriate teacher support and guidance, students can learn to take responsibility for their learning and to access and use the required information. In addition to print sources, students can use:

$>$ Computer networking and telecommunications for data access and participation in learning communities.

$>$ Technological and multimedia sources such as the World Wide Web, CD-ROM, videotape, videodisc, computer software, simulation, and modeling tools.

$>\quad$ Mass media, including televisions, radios, films, newspapers, and magazines

$>\quad$ Local community sources, including social service agencies, libraries, businesses, and individuals with 
The pedagogical utility of audio-visual aids on extrovert and introvert EFL learners' speaking ability

expertise in particular areas.

This will expose the learners to a native like situation and create a more challenging learning method. In working with a text the learner can act freely in a way that if he/she misses a point, he/she can go back and concentrate on it some more, but working in an audio-visual situation makes it impossible to have a second chance, unless it is a teaching material. Working with audio-visual aids is not as easy as the written texts and maybe that's why most teachers especially in Iran avoid it. In this research, all aspects of the problems concerning this matter here are not going to be discussed, but one aspect which it is thought to deserve attention and that is the type of the students attending such a situation. We may come across a lot of problems when working with audio-visual aids such as level of the materials, script (with script or without it), language type (formal/informal), length and that it should be worked as an independent program or as a supplementary one, student type, etc. As mentioned above this research is not going to cover all these areas but one: student type. Concerning this subject psychologically there are two types of students: "Introvert" and "Extrovert".

\subsection{Extrovert and Introvert}

The distinction between introversion and extroversion which was introduced by Jung and has been measured by Eysenck (1970), refers, on the one hand, to the tendency to withdraw from social interaction (introversion) and on the other hand, to the tendency to being outgoing and interested in people and things in the environment (extroversion). He adds that if we emphasize the interpersonal aspects of language learning, extroversion would be an asset, but introversion might well be regarded as advantageous to the systematic study of a language. To be sociable and outgoing is not only a popular stereotype of the good language learner, but also it has some support from a few studies (for example, Pimsleur, 1966; Pritchard, 1952). To be outgoing and inhibited is often also recommended as an appropriate strategy to be adopted by learners particularly in the development of communicative skills (for example Naiman et al., 1978 cited in Stern, 1991, 1993; Rubin, 1975).

Moreover, Eysenck (1975) described introvert and extrovert as follows:

The typical introvert is a quiet, retiring sort of person, introspective, fond of books rather than people. He is reserved and distant except to intimate friends. He tends to plan ahead, looks before he leaps, and mistrusts the impulse of the moment. He doesn't like excitement, takes matters of everyday life with proper seriousness, and likes a well ordered mode of life. He keeps his feelings under close control behaves in an aggressive manner, does not lose his temper easily. He is reliable, somewhat pessimistic, and places greater value on ethical standards. The typical extrovert is sociable, likes parties, has many friends, needs to have people to talk to, and does not like reading and studying by him. He craves excitement, takes chances, often sticks his neck out, acts on the spur of the moment, and is generally an impulsive individual. He is fond of practical jokes, always has a ready answer, and generally likes change, he is carefree, easygoing, optimistic, and likes to laugh and be merry. He prefers to keep moving and doing things, tends to be aggressive and loses his temper quickly, altogether his feelings are not kept under control, and he is not always a reliable person (cited in Aiken, 1989, p. 5).

\subsection{Significance of the Study}

Today in many classes it is recommended to use audio-visual aids to facilitate the language learning process and also to lessen the burden of the teachers' job. The use of such aids can be a great help to both the learner and the teacher, but to what extent? Can every personality type (Introversion/Extroversion) use it efficiently? According to researchers' teaching experience, one group shows to have a greater attention span than the other one and some people seem to get distracted more easily and faster. This study is going to define if this apparent attention span on the part of one group really leads to a better learning and fluency or the other group does a better job despite their short attention span and quicker distraction. Defining this idea may help teachers find 
some make up jobs to compensate the shortcomings of the group which is poor in using audio-visual aids. In other words, by distinguishing these strategies and determining the students' tendency toward introversion or extroversion we may arrive at some helpful conclusions which might be productive in teaching the spoken form of the language both as a receptive skill (listening) and the productive one (speaking).

Earlier researches (Friedlander, 1990; Jones \& Tetroe, 1987; Koboyashi \& Rinnert, 1992) have suggested that the L1 may best be used to plan and organize the speaking while the target language is best for speaking at the sentential level. Results from this study may present a guide to the idea that audio-visual aids might be a benefit for some learners in certain speaking tasks, and later it would be a trigger to consider the value of generating training or coaching materials dealing with speaking and direct strategies for certain aspects of personality traits such as extroversion and introversion. For example, it may provide suggestions as to systematic use of audio-visual aids to develop speaking in certain personality traits which in turn may serve effectively as a means for organizing ideas and expressing themselves in concise, lexically acceptable, and grammatically appropriate.

Results of this study would suggest that the use of audio-visual aids may be beneficial to special learners looking for ways to enhance their L2 speaking and be well-served by materials directing the learners toward the characteristics of fluent speakers in the target language. Thus, the importance of personality types and audio-visual aids on the one hand, and the significance of the speaking ability on the other, has encouraged the present researchers to conduct this study.

\subsection{Statement of the Problem}

In this study the researcher have chosen one aspect of personality called introversion / extroversion in performing speaking task. New findings may present new solutions to the problems such as blocking or reducing of the rate of language learning process. Despite the importance of this matter, i.e. speaking little work has been done on this subject. At least this can be true about the schooling system in Iran, where no or very little attention is paid to speaking. If a student gets interested in conversation they have to go to so much trouble and have self-teaching.

Generally the learners use the strategies of translation, either by thinking in L1 or by using mind translation both of which are invisible. There is a controversy about the usefulness of the translated speaking. Some believe that it is useful because it helps the EFL learner to do a better job in getting fluency in speaking, but some believe that it is counter-productive. There is a tendency in all learners especially in Iran to start the use of spoken form of language using their first language (Persian) in mind and then translating it into English. This can cause a lot of problems the least of which is interference. We can frequently hear sentences like: *I call to my friend, *he married with his cousin, *they are talking together (intending each other), etc. In order to help the learners overcome this problem and create a native like environment for learning English the use of audio-visual aids is highly recommended by some experts. This study is going to define if there is a relationship between the personality type and getting advantage of the blessing of audio-visual aids.

With regard to the rationale of the research, this study is going to answer the following question:

$>\quad$ Is there any statistically significant relationship between introversion/extroversion and the ability in developing fluency in speaking using audio-visual aids?

In order to investigate the above-mentioned research question empirically, the following null hypotheses are stated:

$>\mathrm{H}_{01}$ : There is no statistically significant difference in the speaking performance of Iranian EFL learners taught through audio-visual aids and non-audio-visual ones. 
$>\mathrm{H}_{02}$ : There is no statistically significant difference in the speaking performance of extrovert and introvert Iranian EFL learners.

$>\quad \mathrm{H}_{03}$ : There is no interaction between extroversion/introversion learning style and audio-visual/non audio-visual method of teaching.

\section{Methodology}

\subsection{Participants}

In this study 250 intermediate male students of one of the language schools in Esfahan, Iran who passed pre-intermediate levels, aged between 18-23 took the TOEFL test, interviewed then to make sure they were qualified to the same degree in speaking through which 120 subjects were selected to take the Eysenck Personality Inventory (EPI) and through ranking their marks on the EPI, finally 60 highly introverts and 60 highly extroverts were selected as the main participants. The EPI originates from the Maudsley Personality Inventory (H. J. Eysenck, 1959), the original form of Eysenck Personality Questionnaire (EPQ) (H. J. \& S. B. G. Eysenck, 1975) from which EPI is 3.4. The two mentioned groups were further divided into smaller groups of thirty subjects. One of the introvert groups was considered as the experimental group and the other one as control group. The same procedure was applied to the other groups too. So there were four groups to be studied in this research. Two control groups, one consisting introverts and the other group consisting of the extroverts and two experimental groups consisting introverts and extroverts.

\subsection{Instruments}

In order to reassure the subjects' homogeneousness a standard validated TOEFL test was administered to act as an indicator of subjects' proficiency level. To measure the reliability of the TOEFL test, Cronbach's alpha test was run to ensure its reliability. The result indicated reliability index of 0.821 for this test. Needless to mention, such reliability index proved this test was acceptable for the purpose of the study. It should be mentioned that all the participants have passed at least some nine semesters at one of the language schools in Esfahan, Iran and that's why the term reassure has been used here, because under the strict supervision and assessment applied there, it can be taken for granted that the students attending a level are to a great extent homogenous and any further assessment to define their homogeneity is just a double check. Our purpose is to investigate the spoken skill and see how it can be affected by audio-visual aids and it would be very difficult to get a group of homogenous students by interviewing the subjects, because of being subjective and time consuming. Therefore, a written test was given first and then the subjects were interviewed and rated by three native like speakers. In order to facilitate the job all the interviews were recorded and the CDs were given to the raters to carry out their judgments.

The interviews intentionally were initiated by introducing the interviewee so that the rater could define the candidate's identity. After the first interview which was done as an index to show how much of a command of spoken English one has, the treatment was applied. The treatment was a series of film which was produced for pedagogical purposes in Canada (named How do you do) and comes with the script. For both experimental groups the film was shown with no script and they were asked to watch it carefully, because the teacher was intending to test them later and their class activity score would be based on the score they would get in the interviews. For the other two control groups, the script was used as a teaching material and the teacher taught the items according to usual techniques applied in an ordinary class. After twenty-nine sessions all the students were interviewed again and the recorded interviews were given to the raters to be judged again. It is noteworthy to mention that the raters did not have the records related to the first interview to prevent any Halo/Hawthorn effect. The raters' judgments were compared to what they had done before the treatment was applied and finally the 
Vaezi, R. \& Biria, R., \& Azodi, N.

score of each individual student was compared to see the differences.

\subsection{Procedure}

In order to have homogeneous intermediate participants a standard validated TOEFL test was administered. By computing the mean and standard deviation of the TOEFL test the learners with one standard deviation above and below the mean were selected to take the EPI. The EPI consists of ninety Yes/No questions which should be read once and be answered quickly with a pen so that they cannot change their answers. Then the answer sheets were corrected according to the (E) scoring key. Based on the EPI scores, 30 extroverts and 30 introverts were selected. Moreover, the content validity of EPI was also established through the expert opinion of the three experienced English teachers teaching intermediate EFL learners in several language schools. To meet this purpose, they were asked to express their ideas about the appropriateness of the Eysenck Personality Inventory (EPI) questionnaire, both in terms of the content of the materials and their level. Having shown them the questionnaire, all agreed that the Questionnaire was at the appropriate content and level.

Sometime later the selected participants were interviewed and their answers or explanations were recorded to be rated by three native like raters. The participants were taught some speaking materials in two different methods: The two control groups (one Extrovert and the other one Introvert) were given the texts and taught according to Audio-Lingual Method. The two experimental (Extrovert and introvert) groups were taught by the use of audio-visual aids (film) for some twenty-eight sessions and then interviewed and tested again. The recorded interviews were given to the raters to be rated again. Each participant's performance was compared to his first interview to find out how much progress they have made. As they were intermediate students and during the previous terms they had lots of practices in speaking activities like giving summary, asking and answering questions, dramatizing the dialogs, role-playing, etc.

Three native like raters made assessments on the interviews. Needless to say, they were all experienced English language teachers. All of them had the overall score of 8 in IELTS and had been teaching more than 15 years. As they were the researchers' previous colleagues, they were eager to help. The raters had no information about the participants' background in order to decrease the Halo effect. Next the average of the three scores was computed to reveal each participant's score. Finally, the scores of each personality group and the scores related to their speaking ability were analyzed through applying correlational procedures.

\section{Data Analysis}

\subsection{Data Analysis and Results}

To test the aforesaid null hypotheses a two-way ANOVA was carried out whose results are displayed in Table 1.

\section{Table 1}

The SPSS Output for Two -way ANOVA

\begin{tabular}{llll}
\hline Between-Subjects Factors & & Value Label & $\mathrm{n}$ \\
\hline \multirow{2}{*}{ Treatment } & 1.00 & Experimental & 60 \\
& 2.00 & Control & 60 \\
\multirow{2}{*}{ Extroversion/introversion } & 1.00 & Extrovert & 60 \\
& 2.00 & Introvert & 60 \\
\hline
\end{tabular}


The pedagogical utility of audio-visual aids on extrovert and introvert EFL learners' speaking ability

Table 2

Tests of Between-Subjects Effects

Tests of Between-Subjects Effects

Dependent Variable: VAR00002

\begin{tabular}{llllll}
\hline Source & $\begin{array}{l}\text { Type III Sum of } \\
\text { Squares }\end{array}$ & $d f$ & Mean Square & Fs & Sig. \\
Corrected Model & $406.800(\mathrm{a})$ & 3 & 135.600 & 1.500 & .218 \\
Intercept & 762888.533 & 1 & 762888.533 & 8438.818 & .000 \\
TREAT & 182.533 & 1 & 182.533 & 2.019 & .158 \\
Learning Style & 112.133 & 1 & 112.133 & 1.240 & .268 \\
TREAT * Learning & 112.133 & 1 & 112.133 & & .268 \\
style & 10486.667 & 116 & 90.402 & & \\
Error & 773782.000 & 120 & & & \\
Total & 10893.467 & 119 & & & \\
Corrected Total & & & & \\
\hline
\end{tabular}

Note. a R Squared $=.037$ (Adjusted R Squared $=.012)$

To test the null hypotheses of the present study, the performance of the extrovert and introvert students taught in audio-visual and non-audio-visual classes was compared. A two-way ANOVA was run to compare the performance of the following four groups.

Table 3

Groups of participants

\begin{tabular}{lll}
\hline & Experimental & Control \\
\hline Extrovert & 30 students & 30 students \\
Introvert & 30 students & 30 students \\
\hline
\end{tabular}

The sig. values for all the three types of comparison, as shown in Table 2 were greater than0.05 (the critical value). Therefore, it was concluded that neither the treatment (using audiovisual materials) nor the students' learning style (extroversion vs. introversion), nor the interaction between the treatment and learning style significantly influenced the subjects' performance.

\subsection{Comparison of the Treatment Styles}

Table 2 indicates the difference between the two groups on speaking skill after the treatment was applied. This can show that "Audio-visual" groups are generally more proficient than the "Non audio-visual" groups, but the difference is not prominent. The difference between the lowest score and the highest score is much more in the introvert group than the difference between the lowest and highest score in the extrovert group. The scores among the extrovert learners have more affinity, but the means of the two groups show that the difference cannot be taken into consideration and therefore the null hypothesis is rejected.

\subsection{The Comparison of Personality Types}

The above analysis also shows a comparison of the two introvert groups and two extrovert groups and their speaking ability progress after the treatment application. In both introvert and extrovert groups that received the treatment through audio-visual aids the students did a better job and made more progress. But the sig. values for all the three types of comparison, as shown in Table 2 are greater than 0.05 (the critical value), which statistically cannot be taken into consideration. This can indicate that there is a difference between extrovert and introvert students, regarding being affected by audio-visual aids, but there again the difference is not noteworthy. 
Vaezi, R. \& Biria, R., \& Azodi, N.

3.4 The Interaction between the Treatment Style and Personality Type

Concerning the interaction between the treatment style and personality type, the analysis run in SPSS shows that a sig is .268 which is more than the cutoff point. Therefore, it can be concluded that the interaction between the abovementioned factors is not noteworthy and cannot be taken as a decisive factor of learning into consideration. Considering the three aforesaid analyses the three null hypotheses are all rejected.

\section{Conclusion and Discussion}

To find the relationship between these two pairs of variables a two-way ANOVA was run. It showed that introverts are a bit better at being taught by audio-visual aids, but the difference isn't that great. Kiany (1997, 1998) associated the extrovert language learners with "spontaneous action, examples first, talking and group discussion, social interaction, oral tests, and psychomotor activities" while introverts are associated with "thinking and deep concentration, rules first, reading and verbal reasoning, working alone, written tests and concepts". Based on this finding, it is supposed that introverts are better at speaking because they are more analytic than extroverts. As speaking needs more interaction and concentration it may be assumed that extroverts can show a great difference, but to our surprise this was not the result this study has shown. The reason of this equality may have to be attributed to another difference in the subjects' personality type property. The property that says extroverts are better upstarts. According to this idea extrovert people are very active when they start learning a foreign language and they are more active. As introverts can heed and have deep concentration much easier, they can perform better than extroverts in compensating the shortcomings that they may apparently seem to suffer from, concerning some group activities, class participation, pair work and other activities which require openness to changes and are supposed to be more seen in "Extroverts" rather than "Introverts".

On the contrary, extroverts are better at comprehending the content of the material presented through audio-visual aids, maybe because of their flexibility and sense of the acceptance of foreign culture and language much easier than introverts. They think of the new language as his/her own language and get used to thinking directly in the target language. As Stern $(1991,1993)$ stated, learning a new language demands flexibility and openness to new language norm and norms of social behavior. As it was mentioned before, extroverts go out of their way and even so much trouble to please others. In other words, they are open to changes and accept new things easily to make other people approve of what they do. These two different characteristics in each personality type seem to make for the short coming each one possesses. The introverts do a good job at this level because they use their ability to think and contemplate and the extroverts do as well because of their ability in being flexible and willingness to imitate. Both of these can lead to a better learning and performance. It is worth mentioning that although the extroverts did a bit better, the difference is not noteworthy and cannot be taken as an important point.

Moreover, In order to investigate the effect of audio-visual aids on introvert /extrovert Iranian EFL learners' speaking ability, a two-way ANOVA was also run. The results indicated that there is a significant correlation between extrovert participants. The results of this study also cast doubts on the idea that students who are more apparent active participants in second language learning environment acquire more proficiency in all aspects of the language than those who are less actively involved.

\subsection{Pedagogical Implications}

This study has called attention to the various ways that language students may benefit from audio-visual aids to improve their speaking performance to use language when they want to speak in a foreign language. First, the students may think about the topic or sentence in their first language, as the literature review indicated. Second, they may engage in mental translation, where the translation is in their minds. Earlier researches (Friedlander, 1990; Jones \& Tetroe, 1987; Kobayashi \& Rinnert, 1992) had suggested that LI or the dominant language may be best used to plan and organize the speaking while the target language is best for writing on the sentential 
The pedagogical utility of audio-visual aids on extrovert and introvert EFL learners' speaking ability

levels. Results from this study would support the notion that thinking through L1or the dominant language may be beneficial for some students in certain speaking tasks, and therefore the study seems to lend some support to the value of generating training or coaching materials dealing with speaking strategies for certain personality traits, i.e. introverts.

For example, the materials could provide suggestions for how the systematic use of films or audio might serve effectively as a means for organizing ideas and for expressing them in concise, lexically acceptable, and grammatically appropriate manner. Given the significant relationship between the personality traits and preference of the type of activity the learner favors to develop his/her speaking performance, it would seem that particularly at an intermediate level, training could focus on how students go about selecting appropriate sentences for a given context and the role that the use of audio-visual aids might play in the selection processes.

Simply put, what is implied from this study is that learners can use audio-visual aids to notice the gap in their knowledge by focusing on the items that are problematic for them. In fact, audio-visual aids help learners to alternate their attention between both form and meaning. Needless to say, training materials would need to include a series of caveats, indicating that imitation and memorizing the sample sentences may have a differential effect, depending on the nature of the task (e.g., an in-class free discussion with/without time pressure, an interview, a summary, an oral reproduction, and many others), the topic, or the learning style preferences of the speakers.

To sum up, if learners are truly proactive about the L2 speaking act, they would be well served to determine their own learning style preferences and to ask themselves whether it is beneficial to them to use audio-visual aids to improve their speaking ability. The results of this study would suggest that the use of audio-visual aids may be beneficial to learners looking for ways to enhance their speaking when it is in accordance with their personality type, since it can provide them with appropriate models, authentic pronunciation, and natural-normal rate of fluency.

\subsection{Limitations of the study}

The first limitation of the present study seems to be the sample size which may threaten the validity of the study, and other replications of this study with a larger group may lead to different results. The second limitation is the sex variable. In this research only male learners are going to take part and the result may vary when female subjects are studied. Yet another limitation can be the non-nativity of the raters, although they are all educated and experienced enough, but not being a native speaker may be regarded as a shortcoming of the present study. Lastly, the investigation was conducted only on Iranian EFL learners who are at the intermediate level at some language schools. Thus, the results can be generalized mainly to learners with similar language, cultural, and educational backgrounds and with similar learning experiences.

\section{References:}

Aiken, L. R. (1989). Assessment of personality. Boston: Allyn \& Bacon.

Eysenck, H. J. (1970). Crime and personality (2nd ed.). London: Routledge and Kegan Paul.

Eysenck, H. J. (1975). The biological basis of personality. Springfield, IL: Charles, C. Thomas.

Eysneck , H. J. (1959). The Maudsley personality inventory. London: University of London Press.

Eysneck, H. J., \& Eysneck, S. B. G. (1975).Manual of the Eysneck personality questionnaire (Junior and Adult). London: Hodder and Stonghton.

Friedlander, A. (1990). Composing in English: Effects of first language writing in English as a second language. In B. Kroll (Ed.), Second language writing: Research insights for the classroom (pp. 109-125). Cambridge: Cambridge University Press. http://dx.doi.org/10.1017/CBO9781139524551.012

Jones, S., \& Tetroe, J. (1987). Composition in a second language. In Masuhashi, A. (Ed.), Writing in real time (pp. 34-57). Norwood, NJ: Albex. 
Vaezi, R. \& Biria, R., \& Azodi, N.

Kiany, G. R. (1997). Extroversion and pedagogical setting as sources of variation in different aspects of English proficiency. Orlando Florida: U.S.A.

Kiany, G. R. (1998). English proficiency and academic achievement in relation to extroversion: A preliminary study. International Journal of Applied Linguistics, 8(1), 25-37. http://dx.doi.org/10.1111/j.1473-4192.1998.tb00123.x

Kobayashi, H., \& Rinnehart, C. (1992). Effects of first language on second language writing: Translation versus direct composition. Language Learning, 42, 183-215. http://dx.doi.org/10.1111/j.1467-1770.1992.tb00707.x

Pimsleur, P. (1966). Pimsleur language aptitude battery (PLAB). New York: The Psychological Corporation.

Pritchard, D. F. (1952). An investigation into the relationship of personality traits and ability in modern language. British Journal of Educational Psychology, 22, 157-158. http://dx.doi.org/10.1111/j.2044-8279.1952.tb02817.x

Rubin, J. (1975). What "the good learner" can teach us. TESOL Quarterly, 9, 41-51. http://dx.doi.org/10.2307/3586011

Stern, H. H. (1991). Concepts of language learning: Fundamental concepts in language teaching. Oxford: Oxford University press.

Stern, H. H. (1993). Language factors. Principles of language learning and teaching, 360-390. 